\title{
LA BOÉTIE E KIERKEGAARD: UMA DISCUSSÃO SOBRE A SERVIDÃO VOLUNTÁRIA DO POVO BRASILEIRO
}

\author{
Joanne Ferreira de Oliveira cordeiro(UESB) \\ Jorge Miranda de Almeida (UESB)
}

\begin{abstract}
E disse eu aos nobres, aos magistrados e ao restante do povo: Grande e extensa é a obra, e nós estamos apartados do muro, longe uns dos outros. Neemias 4:19 (Bíblia Sagrada)

Não serei o poeta de um mundo caduco. Também não cantarei o mundo futuro. Estou preso à vida e olho meus companheiros. Estão taciturnos mas nutrem grandes esperanças.

Entre eles, considero a enorme realidade. $O$ presente é tão grande, não nos afastemos. Não nos afastemos muito, vamos de mãos dadas. Não serei o cantor de uma mulher, de uma história, não direi os suspiros ao anoitecer, a paisagem vista da janela,

não distribuirei entorpecentes ou cartas de suicida, não fugirei para as ilhas nem serei raptado por serafins. O tempo é a minha matéria, o tempo presente, os homens presentes, a vida presente.
\end{abstract} Carlos Drummond de Andrade

Resumo: Este artigo, com base n'O discurso da servidão voluntária, de Etienne de la Boétie, e nos postulados de Sören Kierkegaard sobre a subjetividade, discute a sujeição da maioria dos brasileiros diante da improbidade de seus governantes, na tentativa de compreender essa atitude em relação a uma atitude oposta da consciência de si e do seu autêntico papel na sociedade.

Palavras-Chave: Servidão; Brasileiros; La Boétie; Sören Kierkegaard.

Abstract: This article, based on The discourse of voluntary servitude, of Etienne de la Boetie, and Sören Kierkegaard's postulates about the 
subjectivity, discusses the subjection of most Brazilians in front of the improbity of their rulers, trying to understand this attitude compared to an opposite attitude of consciousness of self and of its authentic role in society.

Keywords: Servitude; Brazilians; La Boetie; Sören Kierkegaard.

\section{INTRODUÇÃO}

Os brasileiros estão acostumados à condição de servos, de servir à tirania daqueles que, pela sua própria escolha, por meio do voto, têm legitimada uma posição de poder e liderança política, a qual se dá em detrimento da função para que são designados a agir em favor do bem comum. Certamente há aqueles raros que são escolhidos adequadamente pelo povo, considerando suas virtudes ético-políticas, sua capacidade para cumprir as atribuições a que foram destinados. Entretanto, como disse, são em número tão reduzido, levando-se em conta a dimensão do conjunto do qual fazem parte, que sua força se converte em fraqueza e, pelos artifícios da tirania predominante entre seus pares, ou renunciam ao seu papel de governar, ou são de alguma forma eliminados de seu posto, ou ali permanecem lutando com sua tão pequena força que, contra a tirania, não conseguem feitos capazes de mudar esse estado de exploração, de descaso, de desprezo em que o povo se acha confinado. 
Quero atentar aqui para a grande parte dos brasileiros cuja consciência crítica é tão ausente quanto o seu desejo de deixar o estado de sujeição. Essa massa popular de tal modo manobrada pelos seus desgovernantes se mantém numa miséria física e intelectual, feliz por receber as migalhas da mesa de seus senhores e se sentem na também feliz condição de fazer permanecer no poder aqueles que deliberadamente tratam de providenciar os meios para que as coisas continuem exatamente como estão, senão piores (para os seus servos, é claro).

Assim, percebo que uma maneira viável de lançar sementes de mudança nessa cultura da servidão, ainda que germinando a longuíssimo prazo, é a ação dos educadores.

É bem certo que uma ação como esta não seria iniciativa desse governo tirano nem tampouco deveríamos pensar que ela pudesse ser abrangente demais, mas quero considerar a possibilidade de raros educadores espalhados pelo Brasil irem dando ênfase a uma ação que desperte nos educandos de todas as idades uma competência crítica de sua condição e da condição da sociedade em que se inserem para, a partir daí, exercerem o seu direito, sem dele abrir mão jamais, de interferir no seu contexto contra a servidão e a tirania política. 
Neste estudo, não pretendo me apegar a nomes de pessoas que agem na vida política brasileira nem a fatos políticos específicos, pois entendo que o relevante neste contexto é a dimensão que a improbidade dos governantes vem tomando no Brasil em consonância com a sujeição do seu povo, não sendo necessárias tais referências.

\section{A SERVIDÃO VOLUNTÁRIA DE LABOÉTIE E A CONTEMPORANEIDADE BRASILEIRA}

Étienne de La Boétie foi um filósofo francês de tradição libertária milenarista do século XVI. Escreveu, de título paradoxal, o chamado Discurso sobre a Servidão Voluntária (LA BOÉTIE, 2004). O Discurso foi escrito após a vitória dos exércitos e fiscais do rei, figura do monarca déspota, identificável com o tirano, e fala sobre a população francesa revoltada com a instituição de mais um tributo sobre o sal. Nele, La Boétie revela o desejo da libertação popular autêntica.

O filósofo é de uma época em que o poder ilimitado de um único governante estava começando a ser questionado. $A$ ideia de que os monarcas tinham poder transcendental já não satisfazia. Assim, a intenção de Étienne de La Boétie parece ter sido trazer a compreensão do autêntico direito à liberdade, asseverando o verdadeiro poder que emana do povo; por isso, 
indigna-se contra o cativeiro voluntário, contra a ignorância da existência de qualquer direito na pessoa humana, o que, para ele, é pior que a covardia. No Discurso, há uma ênfase à urgência de se reacender a chama da liberdade em cada ser humano, já que esta lhe é intrínseca.

A maioria das pessoas, hoje, no Brasil, faz exatamente o que La Boétie descreve como sendo a escolha pela ausência da liberdade. Um texto pensado e escrito no século XVI não poderia ser mais atual e mais aplicável à realidade brasileira que estamos presenciando. De fato, o filósofo, refletindo sobre a França de seus dias, parecia antever o nosso contexto político de corrupção, inabilidade, insensibilidade e tudo mais que possa ferir a dignidade humana, tanto dos governantes eleitos quanto dos que os elegem e os mantêm no poder.

No início do texto em estudo, o autor tenta nomear este fenômeno que se observa em muitas civilizações: grande parte do povo servir àquele que lhe faz mal sem qualquer estranhamento:

Mas o que vem a ser isto, afinal? Que nome se deve dar a esta desgraça? Que vício, que triste vício é este: um número infinito de pessoas não a obedecer, mas a servir, não governadas mas tiranizadas, sem bens, sem pais, sem vida a que possam chamar sua? Suportar a pilhagem, as luxúrias, as crueldades, 
não de um exército, não de uma horda de bárbaros, contra os quais dariam o sangue e a vida, mas de um só? [...] Chamaremos a isto covardia? Temos o direito de afirmar que todos os que assim servem são uns míseros covardes? [...] A covardia não vai tão longe, da mesma forma que a valentia também tem os seus limites: um só não escala uma fortaleza, não defronta um exército, não conquista um reino. Que vício monstruoso então é este que sequer merece o nome vil de covardia? Que a natureza nega ter criado, a que a língua se recusa nomear? (LA BOÉTIE, 2004, p.4)

Servir à tirania de um governo, para La Boétie, é algo tão contrário à prática da natural liberdade humana que ele sequer lhe consegue um nome. Em nossa sociedade, esse fenômeno tem se enraizado de tal forma que as pessoas nele envolvidas aceitam tranquilamente a opressão e nela se anulam, o que de fato não é compreensível porque não é próprio do ser humano. Como diz La Boétie, "incrível coisa é ver o povo, uma vez subjugado, cair em tão profundo esquecimento da liberdade que (...) começa a servir com tanta prontidão e boa vontade que parece ter perdido não a liberdade mas a servidão". (2004, p. 12)

O povo brasileiro acostumou-se com o fato de ser usado como instrumento para manter no poder, por incontáveis anos, governantes interessados em fazer permanecer a 
pobreza, a demência política, a ausência de intelectualidade e de criticidade sem questionar-se nesse lugar em que é inteligentemente manipulado, mesmo porque não se vê manipulado; pelo contrário, acredita que sua participação é fundamental nessa "construção da cidadania". Enquanto isso, a habilidade do governo déspota alimenta essa falsa impressão de cidadania com migalhas que deem sobrevida ao rebanho de que ele necessita para se manter. São as conhecidas políticas de reparo, as ações ditas sociais que enganam o necessitado e o mantêm vivo para exercer sua "cidadania", o voto, como gratidão pela liberalidade do seu líder, a qual ainda será louvada nos palanques de comício, nos programas eleitorais de televisão. Por isso é que o escritor assegura que o tirano existe porque o povo o permite. Afirma categoricamente que a vilania é escolha do oprimido; este escolhe e mantém com legitimidade no comando um líder capaz de tirar-lhe tudo o que pode, reservando-lhe, convenientemente, apenas os meios de sua sobrevivência.

Esse que tanto vos humilha tem só dois olhos e duas mãos, tem um só corpo e nada possui que o mais ínfimo entre os ínfimos habitantes das vossas cidades não possua também; uma só coisa ele tem mais do que vós e é o poder de vos destruir, poder que vós lhe concedestes. Onde iria ele buscar os olhos com que vos espia se vós não Ihos désseis? Onde 
teria ele mãos para vos bater se não tivesse as vossas? Os pés com que ele esmaga as vossas cidades de quem são senão vossos? Que poder tem ele sobre vós que de vós não venha? Como ousaria ele perseguir-vos sem a vossa própria conivência? Que poderia ele fazer se vós não fôsseis encobridores daquele que vos rouba, cúmplices do assassino que vos mata e traidores de vós mesmos? (LA BOÉTIE, 2004, p. 7-8)

Percebo, porém, que essa grande massa, especialmente, mas não somente em contextos de municípios brasileiros pequenos, age em benefício da tirania de seu representante e destrói a si mesma sem disso ter consciência, como se nisso houvesse naturalidade; trata-se de um grande rebanho - como veremos adiante nos dizeres de Kierkegaard conduzido ao "curral eleitoral" e sendo alimentado de uma "ração" que toma a forma de favores, empregos, remédios, promessas, enfim, de uma sorte variada de ações cada vez mais desumanizadoras. Estes identificam-se com aqueles descritos por La Boétie na passagem:

É verdade que, a princípio, serve com constrangimento e pela força; mas os que vêm depois, como não conheceram a liberdade nem sabem o que ela seja, servem sem esforço e fazem de boa mente o que seus antepassados tinham feito por obrigação. Assim é: os homens nascem sob o jugo, são criados 
na servidão, sem olharem para lá dela, limitam-se a viver tal como nasceram, nunca pensam ter outro direito nem outro bem senão o que encontraram ao nascer, aceitam como natural o estado que acharam à nascença. (LA BOÉTIE, 2004, p.12)

Como pensa o filósofo francês, quem herda a servidão não imagina outro modo de vida, outro bem ou direito. Por outro lado, também é perceptível o comportamento daqueles que conseguem se ver como meio de manter o tirano, mas que não querem abrir mão dessa posição abominável da troca de favores: "ele/ela pode mais do que eu; então mantenho-o no poder e recebo dele aquilo de que preciso". Não nos é nem um pouco estranho o "apadrinhamento político", a escolha dos cargos de confiança, entre outros conhecidos artifícios de interesse do "cidadão" que não quer perder suas regalias com a saída do tirano do poder. E ainda há que se considerar o fato de que a "política do pão e circo"1 é uma eficaz estratégia da vilania: diverte-se o povo para que ele, feliz, desvie sua atenção da improbidade de seu líder. Façamos menção ao futebol, ao carnaval e a tantos outros "pães e circos" que fascinam os brasileiros. Sobre isso comenta o filósofo:

1 Panem et circenses (ludus): Esta foi uma política criada pelos antigos romanos, que previa o provimento de comida e diversão ao povo, com o objetivo de diminuir a insatisfação popular contra os governantes. 
Atrair o pássaro com o apito ou o peixe com a isca do anzol é mais difícil que atrair o povo para a servidão, pois basta passar-lhes junto à boca um engodo insignificante. É espantoso como eles se deixam levar pelas cócegas. Os teatros, os jogos, as farsas, os espetáculos, as feras exóticas, as medalhas, os quadros e outras bugigangas eram para os povos antigos engodos da servidão, preço da liberdade, instrumentos da tirania. (LA BOÉTIE, 2004, p.18)

La Boétie indigna-se contra essa atitude do povo em louvor à bondade de seu governo ao receber dele aquilo que Ihe é direito e dever deste, e que ainda trata como tendo sido, primeiramente, tirado do povo. Realmente, e aplicando à nossa realidade, o governo, para realizar suas ações, nada mais faz (ou deveria fazer) do que utilizar as arrecadações tributárias da nação, ou seja, o que vem do povo tem de ser restituído a ele em forma de ações que lhe beneficiem. Segundo o autor,

Os tiranos ofereciam o quarto de trigo, o sesteiro de vinho e o sestércio. $\mathrm{E}$ os vivas ao rei eram então coisa triste de ouvir. Não davam conta, os néscios, de que recuperavam dessa forma parte do que era seu e que não podia o tirano dar-lhes coisa que não lhes tivesse furtado antes. (LA BOÉTIE, 2004, p.18) 
Ao contrário do que deveria ser, o que vemos constantemente em nosso país são governantes que utilizam os recursos da nação em benefício de seus próprios interesses em detrimento da assistência às necessidades de seu povo. Como já observei antes, não entrarei no mérito da identificação de fatos nem tampouco de pessoas, já que o que interessa aqui é a discussão de um contexto que se repete há muito no Brasil, mas, se o fizéssemos, não nos faltariam casos para serem citados, cuja repercussão é não só do domínio jurídico como do domínio público.

Um aspecto que quero enfatizar relaciona-se ao fato de que aquele que é colocado no topo para governar o povo conta com seus cúmplices, também eleitos pelo povo, ou seja, abaixo dele, como diz La Boétie, encontra-se "o apoio e o alicerce da tirania". Como esclarece o filósofo:

São sempre quatro ou cinco os que estão no segredo do tirano, são esses quatro ou cinco que sujeitam o povo à servidão. Sempre foi a uma escassa meia dúzia que o tirano deu ouvidos, foram sempre esses os que lograram aproximar-se dele ou ser por ele convocados, para serem cúmplices das suas crueldades, companheiros dos seus prazeres, alcoviteiros de suas lascívias e com ele beneficiários das rapinas. (...) Essa meia dúzia tem ao seu serviço mais seiscentos que procedem com eles como eles 
procedem com o tirano. Abaixo destes seiscentos há seis mil devidamente ensinados a quem confiam ora o governo das províncias ora a administração do dinheiro, para que eles ocultem as suas avarezas e crueldades, para serem seus executores no momento combinado e praticarem tais malefícios que só à sombra deles podem sobreviver e não cair sob a alçada da lei e da justiça. E abaixo de todos estes vêm outros. Quem queira perder tempo a desenredar esta complexa meada descobrirá abaixo dos tais seis mil mais cem mil ou cem milhões agarrados à corda do tirano. (LA BOÉTIE, 2004, p. 24)

Dessa forma, vemos claramente que o tirano não age sozinho. E, especialmente por ocasião de sua reeleição, como é possível em nosso sistema de governo, a cumplicidade dele com os seus se afina para mais uma vez usarem a seu favor a grande massa, os "cem mil ou cem milhões agarrados à corda do tirano". Não é certo que poderíamos entender esses cúmplices como tantos ministros, senadores, deputados, governadores de estado, prefeitos, vereadores, todos interessados na cumplicidade com a vilania para também se manterem no poder por meio da voluntária servidão do povo? 


\section{O “REBANHO” ABORDADO POR KIERKEGAARD E VISTO NO BRASIL DE HOJE}

Recentemente, em nosso país, ocorreu o fenômeno das frequentes manifestações populares, com um lema atraente "Vem pra rua". Nele, vimos um grande número de pessoas saírem às ruas para protestarem contra o estado de coisas que vêm se instalando no cenário político e econômico brasileiro. Não foi identificado um único motivo contra o qual as pessoas protestavam, mas configurou-se como um protesto contra a situação nacional vigente. Aparentemente, víamos uma atitude consciente de pessoas convictas de seu papel como agentes de transformação social. Mas, em sua essência, é possível perceber que não passou de um modismo, de uma onda de influência movida pelas redes sociais, na qual a grande maioria dos manifestantes não dispunham da criticidade necessária para mantê-las nessa posição de vigilância e manifestação contra as circunstâncias de então. O fenômeno não continuou, foi efêmero, teve vida curta. A conjuntura sim, esta permanece: a exploração do empobrecido, a miséria em que a população vive, o descaso com a saúde e a educação, a falência do transporte coletivo e a crise na segurança pública.

Iniciativa de protesto como essa é legítima, porém só vejo significado verdadeiro no protesto de massas se ele for 
constituído pela soma das decisões singulares, das escolhas individuais e não pela manipulação de uns sobre outros, muito menos pela simples imitação como uma espécie de moda que é aderida para se evitar a exclusão, para se alcançar a aceitação social. Soren Kierkegaard, filósofo dinamarquês, chama de "rebanho" o conjunto de sujeitos que segue conduzido pela imitação, pela repetição. Para ele, constituir-se indivíduo, edificar-se como um si mesmo exige afastamento da multidão para que haja um olhar constante para dentro de si e nesse olhar-se é que o indivíduo se vê numa relação com o eterno e com o outro, porém, no rebanho não há interioridade, já que

o eu não é dessas coisas de que o mundo faça grande caso, é com efeito, aquela de que menos curioso se é e que mais risco comporta transparecer que se tem. O pior dos perigos, a perda desse eu, pode nos passar tão desapercebido como se não existisse. Nenhuma perda é mais indiferente, mas qualquer outra, a de um braço, de uma perna, fortuna, mulher, etc., não passa desapercebida. (KIERKEGAARD, 1979, p. 190)

Não é possível, portanto, identificarmos muito do que constituiu o fenômeno das ruas em 2013 como uma atitude de "rebanho"? Não teriam ido às ruas até mesmo os bem intencionados movidos pelo conjunto? E haveria algum mal 
nisso? Sim, se considerarmos que primeiramente importa que o indivíduo seja consciente de si e tenha autonomia na tomada de suas decisões para que a sua ação seja eficaz, capaz de transformar o seu contexto, capaz de converter a servidão em liberdade, o cativeiro em alforria, tanto o seu como o de seu próximo, e, consequentemente, capaz de contribuir para que o bem comum se estabeleça.

E o que é, para Kierkegaard, este eu que precisa ser edificado em cada um para que ele se distinga da multidão e deixe de ser dominado, manipulado? Para Kierkegaard, ser indivíduo é não se encontrar numa estrutura existencial dada, estabelecida. Para constituir-se indivíduo, segundo seu pensamento, é preciso voltar-se para o interior, para a verdade do interior numa relação consigo mesmo e com o poder que o criou. Isso não significa viver ensimesmado, negando os outros indivíduos, mas afastar-se do geral para se constituir e, nessa relação, ao mesmo tempo, projetarse para o próximo. Aí não se dá imitação do outro, mas encontro, relação edificante do "si mesmo", construção de uma subjetividade, um self. ${ }^{2}$ Em O Desespero Humano (Doença até a morte), Kierkegaard afirma que o ser humano é espírito em relação constante.

2 Subjetividade em Kierkegaard diz respeito à verdade da interioridade em que o indivíduo se faz; nela está a sua singularidade, o seu segredo, a sua absoluta subjetividade e também a sua dignidade. A subjetividade liga-se à experiência de voltar-se sobre a relação com o "si mesmo" para se construir e assim encontrar-se com o poder que o criou, com o eterno. 
[...] Mas o que é espírito? Espírito é o self. Mas o que é o self? O self é uma relação, que se relaciona a si mesma, ou o é na relação, que a relação se relaciona a si mesma; o self não é a relação, mas a relação se relacionando a si mesma. O ser humano é uma síntese do infinito e do finito, do temporal e do eterno, de liberdade e necessidade, em resumo, uma síntese. Uma síntese é uma relação entre dois. Assim considerado o ser humano ainda não é um self. (1979, p. 194)

Entendo que, para se imaginar uma sociedade livre da sujeição à tirania, temos, também, que imaginar indivíduos que pensam no sentido mais profundo da palavra. Para Kierkegaard (2010, p. 301), ser um pensador não deveria ser diferente de ser pessoa, e a existência une pensar e existir, pois um existente é um pensador (2010, p. 311). Em Post-scriptum conclusivo não científico às migalhas filosóficas, está evidente que a subjetividade é a verdade, a verdade interior.

Tornar-se um self, encontrar-se na relação na busca do "si mesmo", no entendimento Kierkegaardiano, acontece na relação com Deus, com o Eterno, o que não diz de eximir-se de responsabilidade, mas de realizar sua própria tarefa no conhecimento de si mesmo, no entranhar-se e encontrar o para além de si, que é eterno. A multidão, o rebanho tem 
"carência de infinito", de eterno, de espírito. Em O desespero humano, Kierkegaard assevera que "carecer de infinito comprime e limita desesperadamente" (KIERKEGAARD, 1979, p. 30) e isso seria estreiteza e indigência morais, segundo seu pensamento.

\section{LA BOÉTIE E KIERKEGAARD ENCONTRAM-SE NA PERSPECTIVA DO ETERNO E DA LIBERDADE HUMANA}

É profundo e de intensa humanidade o entendimento a que podemos chegar na aproximação de La Boéti e Kierkegaard. No final do Discurso, o filósofo francês passa a considerar o fato de que na tirania não existe amor, não existe amizade verdadeira (e considero que a única possibilidade de a amizade ser é verdadeira).

A verdade é que o tirano nunca é amado nem ama. A amizade é uma palavra sagrada, é uma coisa santa e só pode existir entre pessoas de bem, só se mantém quando há estima mútua; conserva-se não tanto pelos benefícios quanto por uma vida de bondade. O que dá ao amigo a certeza de contar com o amigo é o conhecimento que tem da sua integridade, a forma como corresponde à sua amizade, o seu bom feitio, a fé e a constância. Não cabe amizade onde há crueldade, onde há deslealdade, onde há injustiça. Quando os maus se reúnem, fazem-no para conspirar, não para travarem amizade. Apoiam-se uns aos 
outros, mas temem-se reciprocamente. Não são amigos, são cúmplices. Ainda que assim não fosse, havia de ser sempre difícil achar num tirano um amor firme. (LA BOÉTIE, 2004, p. 28)

Este amor a que se refere La Boétie, esta fé, esta constância e esta integridade que se encontram no amigo, na amizade, a qual identifica como palavra sagrada, coisa santa, é o que Kierkegaard refere como a síntese do infinito e do finito, do temporal e do eterno, de liberdade e de necessidade, em resumo, a relação em que se dá a construção do "si mesmo", do ser pleno, intenso, que não se confunde com a multidão e não se deixa sujeitar-se a nada que fira a plenitude do "si mesmo". La Boétie, como Kierkegaard, vê no eterno, em Deus, o poder que criou o homem, o amor que destrói a tirania e estabelece a equidade. Assim termina o seu Discurso:

Ergamos os olhos para o Céu, seja por amor da nossa honra, seja pelo amor da própria virtude, olhemos para Deus Todo-poderoso, testemunha certa de nossos atos e justo juiz de nossas faltas. De minha parte, penso, e não me engano, que nada há de mais contrário a um Deus liberal e bondoso, do que a tirania e que ele reserva aos tiranos e seus cúmplices um castigo especial. (LA BOÉTIE, 2004, p. 30)

Então, entendemos na visão desses filósofos que ao homem cabe voltar-se para si mesmo na busca daquele 
que o criou e, encontrando-se com ele, encontra-se consigo mesmo numa relação que não se finda, mas que se edifica constantemente e que direciona para o outro, o seu próximo, o qual passa também a ser sua responsabilidade, sua ética. Mas, para terminar esta minha tarefa, que considero difícil, convido o meu leitor a uma pergunta: Existe alguma maneira de ajudar as pessoas a chegarem a este amor, a esta relação?

\section{A EDUCAÇÃO COMO POSSIBILIDADE DE AS PESSOAS ENCONTRAREM-SE CONSIGO MESMAS}

Como educadora que sou, há muitos anos, vejo na educação uma possibilidade eficaz de despertar o indivíduo, educando para si mesmo, para a sua condição. Comumente, fala-se em construção do sujeito históricocrítico nas escolas. Mas é preciso enfatizar que, antes de tudo, o sujeito deve ser crítico de si mesmo, de sua relação com o mundo que o envolve e de sua relação com aquilo que está para além da materialidade, do físico, que constitui a sua essência, a sua existência.

A educação, por ter se tornado muito reducionista e imediatista, não tem provocado efeitos impactantes nesta nossa realidade enferma, apesar do constante debate em torno das questões educacionais. Especialmente em nosso caso brasileiro, o qual conhecemos de perto, a realidade 
clama diante de nós por uma ação educadora comprometida com a dignidade humana e a justiça social. Entretanto, é necessário que o educador seja, primeiramente, quem se desvista do orgulho, do egoísmo, da autossuficiência e que também se desloque da superficialidade em direção a um mergulho em si mesmo para que se reconheça um ser inconcluso tanto quanto o seu aluno, para, a partir daí, começar um processo de constante revisão de seu papel neste processo tão edificante que é o de educar.

Refletindo sobre essas questões e relacionando Kierkegaard e o educador brasileiro Paulo Freire, Almeida (2013) discute sobre uma educação existencial, por meio da qual o homem percorreria o caminho capaz de orientálo do ponto em que se identifica com o estar vivo até o tornar-se existente. Para este autor, a educação tornase uma alternativa para que haja libertação do indivíduo singular. Segundo seu posicionamento, "não existe revolução verdadeira sem autonomia, decisão pessoal, responsabilidade e engajamento, frutos de uma opção do indivíduo singular" (ALMEIDA, 2013, p. 113). Por isso, ele considera que a transformação das estruturas sociais depende da transformação da mentalidade de cada ser existente, pois, diz Almeida (2013, p. 119), "é no interior do 
"si mesmo" que se trava a maior das batalhas, (...) mas, se não for travada esta luta, o "si mesmo" não será capaz da abnegação e da contribuição para a vida plena". Citando Kierkegaard, ele enfatiza que a abnegação é cristã e que leva o indivíduo a renunciar aos propósitos interesseiros em favor do bem comum (p. 119).

Mais uma vez, quero referir-me a La boétie, pois, assim como os autores citados, ele também vê a educação como o meio para se chegar à libertação. Ele diz que:

há na nossa alma uma semente natural de razão, a qual, se cultivada com bons conselhos e bons costumes, floresce em virtude; se pelo contrário, é atacada pelos vícios, morre de asfixia e aborta. (LA BOÉTIE, 2004, p. 08)

O filósofo francês, nitidamente, referia-se à educação, a qual volta a aludir em outras passagens do Discurso, como em:

São esses dotados de claro entendimento e espírito clarividente; (...) conhecem melhor o futuro e o presente. Além de terem um espírito bem formado, tudo fazem para aperfeiçoá-lo pelo estudo e pelo saber. (LA BOÉTIE, 2004, p. 19)

Para ele, o homem elabora-se pela educação, pelos hábitos da educação, pelos costumes da educação. Por isso é que entendo que a educação precisa ser aquela que leva o homem à autenticidade, à a singularidade, à relação do 
"si mesmo", à, no dizer de Kierkegaard (2005), interioridade do amor que se sacrifica sem esperar recompensa. E, concordando com ele, entendo também que esta é uma condição do educador que abre mão do egoísmo para auxiliar a edificação de singularidades, que decide entregarse a esta tarefa de construir uma educação que possibilita que os educandos se encontrem na relação consigo mesmos e com a sua tarefa de tornar-se singularidade.

A educação que ama, que estima, é uma educação que transforma, que liberta e promove a igualdade, não a servidão.

\section{CONSIDERAÇÕES FINAIS}

Em um contexto em que o homem se deixa dominar pelo outro voluntariamente e em que esse outro é identificado como o seu líder governamental, há uma necessidade de que os que não se deixam dominar se aproximem uns dos outros e incentivem-se ao rompimento com as cadeias da servidão.

A intensa massificação da sociedade, a sua transformação em rebanho, a sua coisificação clama por uma transformação rumo à libertação do indivíduo, que se reduziu a um número. A redução do humano a ser mais um tornou-se um instrumento útil para a tirania se manter no poder. Dessa forma, não há interesse do governo em promover ações que sejam libertadoras, mas sim que mantenham o povo na 
escravidão, alimentados pelo "pão e circo"; os tiranos que se legitimam no comando pela decisão do povo procuram permanecer como mandatários por todo o sempre.

É então no sentido de quebrar as correntes da servidão que entendo a educação como um meio eficaz de agir contra a animalização do homem e a edificação de sua singularidade. Edificar as singularidades é possibilitar ao indivíduo tornar-se sempre, mover-se rumo a sua própria existência e, consequentemente, à existência do seu próximo, também como uma responsabilidade sua. A mudança social do servilismo para a liberdade passa pela construção do indivíduo singular, o qual age e toma decisões por escolha própria.

Mais uma vez, então, afirmo que, em nosso contexto brasileiro de acorrentamento e condução das pessoas, é preciso que haja uma decisão dos educadores singulares, conscientes do "si mesmo", no sentido de agirem movidos pelo amor que edifica e que transcende que tem a edificação do outro no encontro consigo mesmos também como uma responsabilidade sua.

\section{REFERÊNCIAS}

Almeida, J.M. (2013). A educação em Kierkegaard e Paulo Freire: por uma educação ético-existencial. Vitória da Conquista: Edições UESB.

La boétie, E. (2004). Discurso Sobre a Servidão Voluntária. Cultura 
Brasileira. In http://www.culturabrasil.pro.br/zip/boetie.pdf. Acesso em maio/2011.

Kierkegaard, S. (1979). O Desespero Humano (Doença até a morte). In coleção Os Pensadores. Rio de Janeiro: Abril Cultural. (2005). As obras do amor. Petrópolis: Vozes.

(2010). Post-scriptum conclusivo não científico às migalhas filosóficas - opere. Milano: Sansoni Editore.

Jorge Miranda tem Mestrado, Doutorado e Pós-doutorado em Filosofia. É Prof. titular DFCH-UESB, prof. programa permanente do PPGMLS-UESB-BA. (Mestrado e Doutorado) em Memória: Linguagem e Sociedade; prof. colaborador PPG Linguística UESB-BA. É coordenador do Grupo de Pesquisa - CNPQ - Memória, subjetividade e subjetivação no pensamento contemporâneo. Contato: mirandajma@gmail.com.

Joanne Cordeiro está concluindo o Mestrado em Memória, Linguagem e Sociedade, pela Universidade Estadual do Sudoeste da Bahia - UESB - e, como já está aprovada em seleção, iniciará o Doutorado em Março de 2015 no mesmo Programa e instituição. É pesquisadora no Grupo de Pesquisa - CNPQ - Memória, subjetividade e subjetivação no pensamento contemporâneo. Contato: joanneportugues@hotmail.com. 